$\begin{array}{cc}\text { http://www.jrdms.dentaiau.ac.ir } & \mathrm{e}(\mathrm{ISSN}): 2383-2754 \\ \mathrm{p}(\mathrm{ISSN}): 2588-4166 & \\ \text { JRDMS Journal of Research in Dental and Maxillofacial Sciences }\end{array}$

\title{
Perspective of Senior Dental Students About the Priorities for Instructor Evaluation
}

\author{
Kheirbakhsh $\mathrm{SH}^{1 *}$, Alaee $\mathrm{A}^{2}$, Shahsavari $\mathrm{F}^{3}$, Dehnoee $\mathrm{M}^{4}$ \\ ${ }^{1}$ Post Graduate Student, Oral Medicine Dept, Dental Branch of Tehran, Islamic Azad University, Tehran, Iran \\ ${ }_{2}^{2}$ Assistant Professor, Oral medicine Dept, Member of Dental Material Research Center, Dental Branch of Tehran, Islamic Azad University Tehran, Iran \\ ${ }^{3}$ Assistant Professor, Oral and Maxillofacial Pathology Dept, Dental Branch of Tehran, Islamic Azad University, Tehran, Iran \\ ${ }^{4}$ Dentist
}

\begin{tabular}{l}
\hline ARTICLE INFO \\
\hline Article Type \\
Original Article \\
\hline Article History \\
Received: Apr 2017 \\
Accepted: May 2017 \\
ePublished: June 2017
\end{tabular}

Keywords:

Teaching Methods,

Education,

Evaluation,

Communication,

Satisfaction,

Dental Students

\begin{abstract}
Background and Aim: Regular evaluation of the efficiency of instructors is highly important to promote the quality of instruction. This study aimed to assess the perspective of senior dental students about the priorities that must be considered in instructor evaluation.

Materials and Methods: In this descriptive study, the significance of instructor assessment from the viewpoint of 132 senior dental students was evaluated in five domains of teaching skills, personal characteristics and skills, communication skills, adherence to educational regulations, and assessment skills. The frequency of the overall significance of each item and the domains as well as the effect of demographic and socioeconomic factors on the results were analyzed by Chi-square test.

Results: $84.4 \%$ of students believed that instructor assessment was important. Teaching skills acquired the highest score $(90.6 \%)$, followed by communication skills $(89.4 \%)$, personal characteristics and skills $(83.8 \%)$, and educational regulations $(70.9 \%)$ with statistically significant differences $(\mathrm{P}<0.0001)$. Students gave the highest score to the teaching method $(98.5 \%)$, followed by the ability to well discuss the topic, conveying the topic, and mastery of the content $(96.2 \%)$. The lowest score was given to the adherence to the order of educational contents set by the educational committee $(42 \%)$ and to the usefulness of homework (49\%). No significant association was noted between gender, age, grade point average (GPA), the parents' occupation, or interest in dentistry as a profession with the students' opinions about the instructor assessment form and the five domains $(\mathrm{P}=0.2)$.

Conclusion: Educational workshops may enhance the teaching and communication skills of instructors, may increase the satisfaction of students with the instructors' performance and may yield greater educational achievements.
\end{abstract}




\section{Introduction:}

Knowledge about the priorities to be considered in instructor evaluation according to the perspective of students is important to promote the quality of education. ${ }^{(1)}$ Dental education is a highly sensitive topic since dental graduates deal with people's lives. Thus, many attempts have been made to promote the quality of dental education. Instructors play a fundamental role in this respect, and therefore, constant monitoring of their performance and quality of instruction is imperative. ${ }^{(2,3)}$ Evaluation of the efficiency of instructors by their students is performed to improve the quality of instruction by providing the instructors with feedback from students. ${ }^{(2)}$

The results of instructor evaluation are assessed and prioritized by the authorities to promote the quality of instruction accordingly. ${ }^{(4)}$ This assessment reveals the limitations and the strengths of instruction and allows for further reinforcement of the strengths and elimination and correction of the weaknesses and limitations. ${ }^{(5)}$

At present, the students' perspectives are used along with many other quality control and monitoring systems in many universities worldwide to assess the quality and efficiency of instruction. $^{(5)}$ In this method, students are often provided with a questionnaire containing several questions regarding the educational activities of their instructors. By filling out this questionnaire, students rate the performance of their instructors. ${ }^{(6,7)}$ The opinions of students are used for making a decision with regard to the academic ranking of instructors, changing their employment status, or providing them with a scholarship. Moreover, the opinions of students are used to resolve the existing problems and shortcomings in the educational system. Also, the strengths and limitations of instructor evaluation forms can be detected, and the shortcomings can be eliminated by those in charge. By using this information, the authorities can modify the forms to obtain more accurate information about the actual performance of instructors. ${ }^{(1)}$

Previous studies on this topic have had some shortcomings such as too many questions, in- adequate number of questions, uneven distribution of questionnaires, or questionnaire distribution at an inappropriate time or place. ${ }^{(9-11)}$ Also, a search of the literature by the authors did not yield any study on the priorities to be considered in instructor evaluation forms according to the perspectives of dental students. Considering the fact that dental students work closely with their instructors for acquiring clinical skills, this study aimed to assess the nriorities to he considered in

; to the per-

\section{Methods and Materials:}

This descriptive cross-sectional study was performed on 132 senior dental students of the dental branch of Islamic Azad University in the second trimester of 2015.

Data were collected by using a questionnaire $(1,11)$ which contained a demographic section and the main part. The demographic part included six questions regarding age, gender, grade point average (GPA), father's occupation, mother's occupation, and interest in dentistry as a profession.

The significance of instructor assessment from the viewpoint of students was evaluated through 20 items in five domains of teaching skills, personal characteristics and skills, communication skills, adherence to educational regulations, and assessment skills. In terms of the significance, each item was reported to be highly important, less important, or not important. The frequency of the overall significance of each item and the domains as well as the effect of demographic and socioeconomic factors on the results were analyzed by using Chi-square test via SPSS version 22 software program (IBM Co., Chicago, IL, USA).

\section{Results:}

This descriptive study was conducted on 132 dental students. There were 42 males $(31.8 \%)$ and 90 females $(68.2 \%)$. Their mean age was $26.4 \pm 4.1$ years, and their GPA was $15.7 \pm 1.1$. Figure 1 shows the frequency distribution of stu- 
dents in terms of their opinion regarding the significance of instructor assessment. $41 \%$ of students believed that instructor assessment was highly important, $43.4 \%$ believed that it was important, $13.6 \%$ believed that it was not very important, and $2 \%$ believed that it was not important at all. Overall, $84.4 \%$ of students believed that instructor assessment was important, while $15.6 \%$ of students believed that it was not important.

Table 1 shows the frequency distribution of students in terms of their opinion regarding the instructor assessment domains. As shown, teaching skills acquired the highest score in terms of the significance (very important and important; 90.6\%), followed by communication skills $(89.4 \%)$ and personal characteristics and skills (83.8\%). Educational regulations acquired the lowest score $(70.9 \%)$. According to Chi-square test, the difference in the opinions of students regarding the significance of instructor assessment was statistically significant $(\mathrm{P}<0.0001)$.

Also, of the twenty items in the aforementioned five domains, students gave the highest score (most important) to the teaching method (98.5\%), followed by the ability to well discuss the topic, conveying the topic, and mastery of the content (96.2\%). The lowest score (least important) was given to the adherence to the order of educational contents set by the educational committee $(42 \%)$ and to the efficacy and usefulness of homework $(49 \%)$.

No significant association was noted between gender, age, GPA, the occupation of the parents, or interest in dentistry as a profession with the students' opinions regarding the instructor assessment form and the five domains $(\mathrm{P}=0.2)$.

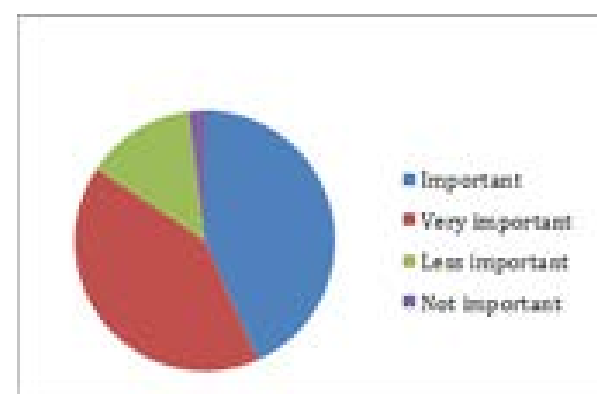

Figure 1- Frequency distribution of the dental students' viewpoints about the significance of instructor assessment

\section{Discussion:}

The results of the current study showed that $84.4 \%$ of students believed that instructor assessment was important, while $15.6 \%$ of students believed that it was not important. The teaching method acquired the highest score, followed by the ability to well discuss the topic, conveying the topic, and mastery of the content. The lowest score (least important) was given to the adherence to the order of educational contents set by the educational committee and to the efficacy and usefulness of homework. The findings of the present study were in agreement with those of many previous studies.

Kerman Saravi et al evaluated the viewpoints of faculty members and nursing students towards the priorities in instructor evaluation. ${ }^{(1)}$ A total of 245 students and 26 instructors were evaluated by using a researcher-designed questionnaire. The most important priorities from the teachers' and students' viewpoints were related to teaching skills, mastery of the topic, creating motivation, and students' participation in instruction, respectively.

Table 1. Frequency distribution of the dental students' viewpoints about the significance of instructor assessment categorized by the domains

\begin{tabular}{llll}
\hline \multicolumn{1}{c}{ Domain } & Important (\%) & Not important (\%) & Total (\%) \\
\hline Teaching skills & $1027(90.6)$ & $106(0.4)$ & $1133(100)$ \\
\hline $\begin{array}{l}\text { Personal characteristics and } \\
\text { skills }\end{array}$ & $332(83.8)$ & $64(16.2)$ & $396(100)$ \\
\hline Communication skills & $354(89.4)$ & $42(10.6)$ & $396(100)$ \\
\hline Educational regulations & $280(70.9)$ & $115(29.1)$ & $395(100)$ \\
\hline Assessment skills & $298(75.3)$ & $98(24.7)$ & $396(100)$ \\
\hline
\end{tabular}


Their results were in agreement with ours. The highest priority was given to teaching skills and communication skills, while assessment skills and educational regulations had the lowest priority. However, Kerman Saravi et al compared the students' and teachers' perspectives and found interesting results. ${ }^{(1)}$ Moreover, they included an open question in the questionnaire and found that $30.8 \%$ of faculty members and $55 \%$ of students believed that the assessments were truly accurate, while $71 \%$ of faculty members and $80 \%$ of students believed that the evaluation form cannot accurately assess the quality of instruction. ${ }^{(1)} \mathrm{We}$ did not include such a question in our questionnaire; thus, no comparison can be made on this topic between the two studies.

Rafeey and Javadzadeh evaluated the factors affecting the quality of instruction according to the point of view of residents of Tabriz University of Medical Sciences in 2009. ${ }^{(2)}$ They evaluated 360 residents by using a researcher-designed questionnaire with 44 questions in four main domains of clinical training, educational rules and regulations, knowledge and skills of instructors, and personal characteristics and behavior of instructors. In the clinical training domain, $94.4 \%$ of residents reported education during surgical operation to be the most important item, followed by management of clinical courses $(90.5 \%)$, teaching ethics in medicine $(91.3 \%)$, instruction of proper treatment of patients $(90.3 \%)$, management and care for patients with specific diseases $(91.6 \%)$, and general visit of patients $(88.2 \%)$.

The ability to convey the topic $(86 \%)$ acquired a high score in the teaching ability domain, and non-judgmental and non-humiliating behavior acquired a high score $(79 \%)$ in the personal characteristics domain. The instructor's knowledgeability and expertise acquired a high score $(93.5 \%)$ in the knowledge and skills domain. ${ }^{(2)}$

From the residents' point of view, the most important educational domain affecting the evaluation of academic members was the clinical instruction domain $(4.39 \%)$ and the instructor's knowledgeability and expertise $(4.29 \%) .^{(2)}$ In general, their findings were in agreement with our results regarding the highest priority given to the knowledge and skills of instructors and the lowest priority given to educational rules and regulations. However, they also evaluated the performance of instructors in clinical instruction from the students' perspectives, which is valuable and was not evaluated in our study.

Currently, not only the professional skills and comprehensive knowledge but also the ability to comprehend and convey the educational content and acquaintance with novel educational techniques are necessary for instructors; interactive instruction has replaced one-way instruction. ${ }^{(12)}$ The efficiency of instruction must be improved to educate knowledgeable graduates. Instructor evaluation is a necessary step to achieve this goal, to find out the shortcomings and obstacles against efficient instruction, and to eliminate them. The priorities in this respect must also be evaluated from the students' point of view. ${ }^{(13)}$

The quality of instruction is a highly important topic that should not be disregarded in instructor evaluation when it comes to clinical practice. However, a question arises that whether this topic can be assessed by only a few simple questions asked in a questionnaire. Considering the significance of this topic, future studies are required to assess the perspectives of students regarding the efficiency and quality of clinical instruction in different fields such as restorative dentistry, prosthodontics, endodontics, pediatric dentistry and so on to better elucidate this topic. To better scrutinize this topic, senior dental students and postgraduate students can be interviewed face to face to collect their opinion about the quality of clinical instruction.

Regarding the next important priorities namely personal characteristics, assessment skills, and educational rules and regulations, it should be mentioned that sometimes, the instructor is knowledgeable and has a high academic ranking but he/she cannot properly convey the topic to students, and this negatively affects his/her assessment scores. In other words, students can sense the presence or absence of self-esteem in their instructors. In the current study, students gave a low score to academic rankings of instructors. These findings indicate the significance of the further study of the topic by the instructor, reinforcing the internal motives (polished look, having a sense of humor), improving personal characteristics and skills, and holding workshops or continuing education courses on novel methods of instruction by the EDO in universities. ${ }^{(1-4,14,15)}$ 
Distribution and collection of the questionnaires were among the limitations of this study. Future studies are required to qualitatively assess the validity and reliability of assessment tools.

A specific questionnaire must be designed based on the opinions of instructors, residents, and undergraduate students and it must be revised by the professional committees (such as the EDO). Also, self-assessment of instructors and frequent assessment at different time points may yield interesting results. In addition, incentives must be considered for superior instructors to further encourage them for an efficient instruction. ${ }^{(15)}$ Moreover, at the end of each course, the instructor can simply ask the opinion of students about his/her performance and quality of teaching. This may be even more effective than the traditional method of instructor evaluation.

\section{Conclusion:}

Educational workshops may enhance the teaching and communication skills of instructors, may increase the satisfaction of students with the instructors' performance and may yield greater educational achievements.

\section{Acknowledgement:}

This article is based on General Dentistry Thesis,No:25008. Also, we are thankful to Mr. Naser Valaei regarding to his cooperation in preparing of statistical analysis.

\section{References:}

1-Kerman Saravi F, Navidian A, Navabi Rigi Sh. Nursing Students Teachers' view points toward priorities in Teachers Evaluation. IJN 2011 Oct;24(72):18-28.

2-Rafeey M, Javadzadeh A. Effective factors in evaluation of university professors' teaching: clinical residents' point of view in Tabriz University of Medical Sciences. IJME. 2011;11(3):26978.

3-Fesharakinia A, Khazaei T, Khazaei Z, Mohammadpoor M. Assessment of Birjand Medical School Students' attitudes toward the criteria of academic evaluation in 2009. Mod Care J 2012;9(1):49-56.

4-Hossini M, Sarchami R. Attitude of students of Qazvin Medical University towards priorities in teacher's assessment. J Qazvin Univ Med Sci 2002,6(2): 33-7.

5-Heidari H, Sharifirad GhR, Kamran A. A comparative study of teacher evaluation priorities from viewpoint of the faculty members and students of Lorestan University of Medical Sciences. Health Sys Res. 2013;9(7):749-59.

6-Seif A. Teacher evaluation using students' view point: Is it reliable? Psychol Res. 1997;1:12-24.

7-Thompson Bowles T. The evaluation of teaching. Med Teach. 2000;22(3):221-4.

8-Jafari H, Vahidshahi K, Kousarian M, Mahmoudi M. Comparison between the results of academic staff self-assessment and those made by the students, Faculty of Medicine, Mazandaran University of Medical Sciences, 2006. J Mazandaran Univ Med Sci. 2007;17(57):67-74.

9-Yaghobian M, Yaghobi T, Salmeh F, Golmohammadi F, Safari H, Savasari R, et al. Comparing the Effect of Teaching Using Educational Booklets and Lecture along with Educational Booklets on Nurses' Knowledge about Professional Laws and Regulations. Iranian J Med Educ. 2010; 9(4):372-80.

10- Asgari F, Mahjoob Moadab H. Comparing characteristics of an effective teaching from teachers' and students' point of view, Guilan University of Medical Sciences. Strides Dev Med Educ. 2010;7(1):26-33.

11- Taqi HA, Al-Nouh NA, Dashti AA, Shuqair KM. The Perspectives of Students and Teachers in the English Department in the College of Basic Education on the Student Evaluation of Teachers. JEL;2014;3(4):71-89.

12- Baral N, Puadel BH, Das BK, Aryal M, Guatam A, Lamsal M. Preparing tutors for problem-based learning: an experience from B. P. Koirala Institute of Health Sciences, Nepal. Kathmandu Uni Med J(KUMJ). 2010;1(29):141-5.

13- Hornstein H A. Student evaluations of teaching are an inadequate assessment tool for evaluating faculty performance. Cogent Education 2017; 4: 1304016.

14- Amini M, Honardar M.The view of faculties and medical students about evaluation of faculty teaching experiences. Koomesh. 2008;9(3):171-8. 15-Turhon K, Yaris F, Nural E. Does instructor evaluation by students using a WEB-based questionnaire impact instructor performance? Adv Health Sci Educ Theory Pract. 2005;10(1):5-13. 